\title{
The effect of 8 weeks moderate-intensity continuous training on central hemodynamics and $\mathrm{VO}_{2 \max }$ in non-athlete male
}

Javad Mahdiabadi ${ }^{\mathrm{ABCDE}}$

Toos Institute of Higher Education, Mashhad, Iran

Authors' Contribution: A - Study Design, B - Data Collection, C - Statistical Analysis, D - Manuscript Preparation, E - Funds Collection

\begin{tabular}{|c|c|}
\hline & \\
\hline $\begin{array}{l}\text { Background } \\
\text { and Study Aim }\end{array}$ & $\begin{array}{l}\text { erobic exercise improves fitness and quality of life and decreases mortality rate. Existence study } \\
\text { etermined the central hemodynamic adaptation after } 8 \text { weeks moderate-intensity continuous } \\
\text { ountryside jogging in non-athlete male. }\end{array}$ \\
\hline $\begin{array}{l}\text { Material and } \\
\text { Methods }\end{array}$ & $\begin{array}{l}\text { Twenty-four untrained healthy male students (aged } 20-22 \text { years) volunteered and randomly divided into } \\
\text { two groups: continuous training (CTG; } n=12) \text { and control }(C G ; n=12) \text {. Training program was countryside } \\
\text { jogging for } 45 \text { min at } 65-70 \% \text { of Maximum Heart Rate }(M H R), 3 \text { days/week for } 8 \text {-weeks performed. The } \\
\text { CG group remained sedentary during the study period. Maximal oxygen consumption }\left(\mathrm{VO}_{2 \max } \text { ) obtained }\right. \\
\text { using the step-test. Standard medical method impedance cardiograph was performed for hemodynamic } \\
\text { parameters, during resting and after step-test conditions, before and after the study period. }\end{array}$ \\
\hline Results & $\begin{array}{l}\text { Using t-test, after eight weeks: the resting heart rate }(H R) \text { in } C T G \text { group significantly decreased }(P \leq 0.05) \text {. The } \\
\text { systolic blood pressure (SBP) in CTG group decreased significantly at rest and after workload }(P \leq 0.05) \text {. The } \\
\text { diastolic blood pressure (DBP) did not change in both groups }(P>0.05) \text {. The stroke volume }(S V) \text { increased } \\
\text { significantly in CTG group at rest and after workload }(P \leq 0.05) \text {. The cardiac output }(C O) \text { did not change in } \\
\text { both groups ( } P>0.05) \text {. The cardiac output }(C O) \text { did not change in both groups }(P>0.05) \text {. The VO }{ }_{2 \max } \text { absolute } \\
\text { and relative increased significantly in CTG group }(P \leq 0.05) \text {. Significant difference between groups in } S B P, \\
\text { SV, SVR and } \mathrm{VO}_{2 \max } \text { (absolute and relative) }(P \leq 0.05) \text {. }\end{array}$ \\
\hline Conc & $\begin{array}{l}8 \text { weeks moderate-intensity continuous countryside jogging can improve the cardiac function and } \\
\mathrm{VO}_{2 \max } \text { in selected healthy male. The regular exercise of aerobic with moderate intensity causes positive } \\
\text { developments in systolic and diastolic blood pressures. } \\
\text { heart rate, stroke volume, systemic vascular resistance, jogqing, maximal oxygen consumption }\end{array}$ \\
\hline
\end{tabular}

\section{Introduction}

Reduce cardiovascular risk as a result of regular physical activity [1]. Many researches have reported that endurance training increases cardiac systolic function reserve [2]. Studies confirm that the health benefits of endurance training and people try to establish it as a part of daily life [3,4]. Aerobic trainings as a kind of workload program advised for health improvement and prevention for many cardiovascular diseases specially prevent or delay the development of hypertension (systolic blood pressure $(\mathrm{SBP})>140 \mathrm{~mm} \mathrm{Hg}$ and diastolic blood pressure (DBP) $>90 \mathrm{~mm} \mathrm{Hg}$ ) [5, 6]. They refer to all trainings that involving major muscle groups and improve oxygen consumption. Many methods of aerobic training are available like walking, jogging, running, cycling and others [7-9]. Recent studies confirm that aerobic exercise would result in clinically significant reduction in blood pressure [7]. BP change during the aerobic training may relate to variations in underlying physiological adaptive processes (e.g., neural, hormonal, and local vasodilator substances) $[10,11]$.

Effect of regular exercise on Hemodynamic specifically, changes in cardiac output $(\mathrm{CO})$ and peripheral vascular resistance due to exercise, it depends on sporting disciplines. Exercise can be separated into two types

(c) Javad Mahdiabadi, 2021

doi:10.15561/20755279.2021.0305 with defining hemodynamic differences. Isotonic type, as endurance exercise increased in $\mathrm{CO}$ with normal or reduced peripheral vascular resistance. This type of exercise primarily represents a volume challenge for the heart, which affects all four chambers, specially increased left ventricular chamber size, with an increase in wall thickness caused by volume overload (eccentric left ventricular hypertrophy). In contrast, isometric exercise, as strength training, leads to increased peripheral vascular resistance, and normal or only little increased $\mathrm{CO}$. The increase in peripheral resistance causes momentary but potentially marked systolic hypertension and left ventricular afterload. Athletes involved in mainly static or isometric exercise develop increased left ventricular wall thickness, with no change in left ventricular chamber size (concentric left ventricular hypertrophy) $[12,13]$.

The $\mathrm{CO}$ is altered by regulating both heart rate (HR) and stroke volume (SV) [14]. Regular exercise and physical activity cause a reduction in resting heart rate (RHR) [15, 16]. Cramer et al. [15] found a significant reduction in heart rate through yoga of $6.59 \mathrm{bpm}$ in in healthy participants. In another studies Huang G, Shi et al. [17] showed that endurance training causes RHR reductions of $8.4 \%$ in older individuals. Furthermore, a decrease in RHR at quiet status was found after tai chi exercise in healthy adults in the research of Zheng Li et al. [18]. 
The increase in maximal heart rate (MHR) is responsible for enhancement of the $\mathrm{CO}$ during exercise, and peak HR is a basically limiting factor of peak exercise capacity in healthy people. Maximal HR does not increase with training. In contrast, with prolonged physical training increases in stroke volume (SV) at rest and during exercise [19]. The initial increase in SV during training is as a result of an improved systolic and diastolic function as indicated by a raise in venous return and a stronger myocardial contractility. Additional research by Slordahl et al. [20] demonstrated that high intensity aerobic training at $90-95 \%$ of maximal oxygen consumption $\left(\mathrm{VO}_{2 \max }\right)$ increased left ventricle heart mass by $12 \%$ and cardiac contractility by $13 \%$, which is comparable to cardiovascular changes observed in continuous aerobic exercise. LV filling pressures and diastolic LV distension increase at the onset of exercise causing stretch-activation of myofibers according to the Frank-Starling mechanism and subsequently an increase in SV [21]. Findings about the $\mathrm{CO}$ help to develop physiological responses and mechanisms of adaptation due to the physical training, sedentary lifestyle and chronic disease [22].

Maximal oxygen consumption $\left(\mathrm{VO}_{2 \max }\right)$ is considered the uppermost ability of the body to consume, distribute and utilize oxygen for energy production. It is commonly called maximal aerobic capacity and is a good predictor of exercise performance. Improvements in cardiovascular function will increase one's $\mathrm{VO}_{2 \max }$. Daussin et al. [23] measured $\mathrm{VO}_{2 \max }$ responses among men and women who participated in an 8-week interval and a continuous cardiovascular training program. $\mathrm{VO}_{2 \max }$ increases in the interval group (15\%) and in the continuous group $(9 \%)$. Several study reported that the $4 \times 4$-min high-intensity interval training approach has been shown to be more effective than moderate exercise training for improving maximal oxygen uptake $\left(\mathrm{VO}_{2 \max }\right)$ in both healthy subjects and patient groups [24-26]. Improving cardiovascular function and increasing $\mathrm{VO}_{2 \max }$ are major goals of patients that suffer from cardiovascular disease [27].

Many people who want to do sports practice in different exercises. But what kind of cardiovascular exercise more effective than it is important to clearly specify. The aim of this study determined the central hemodynamic adaptation after 8 weeks moderate-intensity continuous countryside jogging in non-athlete male.

\section{Material and methods}

\section{Participants.}

The study was performed on 24 non-athletic healthy male students aged from 18-22 years. Selected participants were randomly divided into two groups as continuous training group (CTG; $\mathrm{n}=12)$ and control group $(\mathrm{CG} ; \mathrm{n}=12)$. They did not attend regularly sports activities (more than one hour per week), before this study. The criterion for cardiovascular health was the data obtained from the questionnaire devised by the researcher. Before the initiation to participate in the study, all subjects were informed of the process and filled out the medical sport questionnaire and the consent form.
Research Design.

\section{Training programme.}

Training program was designed including a 45-minutes countryside continuous jogging with $65-70 \%$ of the maximum heart rate (MHR), three times a week for eight weeks. Training session was of $65 \mathrm{~min}$ duration and consisted of warm-up (10min), main program (45min) and cold-down $(10 \mathrm{~min})$. All the training sessions were supervised by the researcher. The control group remained sedentary during the study period.

Complex «Impecard-M TU RB14563250. 017-96. » was used to study central hemodynamics (HR, SV, CO, SVR) with application of standard medical method of tetra polar chest reography (impedance cardiograph).

Blood pressure (BP) were recorded in the sitting position. BP at rest was obtained from the right arm was resting on a table with the elbow in a flexed position by manually using mechanical aneroid sphygmomanometer and a quality stethoscope (MDF ${ }^{\circledR}$ Calibra Professional Aneroid Sphygmomanometer and Stethoscope). The resting heart rate (HR) was recorded by 60 -s count, maximum heart rate was determined by the formula:

$\mathrm{HR}_{\max }=220-$ age.

Step-test uses as a $40 \mathrm{~cm}$ high step bench. Subjects try with a step frequency of 22.5 steps per minute under the metronome for 6 minutes. Aerobic capacity was expressed as estimated maximal oxygen consumption $\left(\mathrm{VO}_{2 \max }\right)$, obtained using the step-test and the AstrandRyhming nomogram from the steady state heart rate (HR) and workload [28].

Statistical analysis.

SPSS 19.0 packet program. Means and standard deviation were calculated with this program. Test of normality for the data's were made by KolmogorovSmirnov test. And then parametric tests applied. The evaluation inside the group was made by Paired Samples- $t$ test, and evaluations between-group differences in baseline values and intervention induced changes were tested by independent- $t$ test. Statistical significance was accepted as and $\mathrm{p} \leq 0.05$.

\section{Results}

General features and demographic characteristics of the participants are summarized in Table 1. Values of central hemodynamic variables participants are summarized in Table 2. After eight weeks the resting heart rate (HR) in the CTG significantly decreased $(\mathrm{P} \leq 0.05)$. The systolic blood pressure (SBP) in CTG decreased significantly at rest and after workload $(\mathrm{P} \leq 0.05)$. The diastolic blood pressure did not change in both groups $(\mathrm{P}>0.05)$. The systemic vascular resistance (SVR) in both groups did not change $(\mathrm{P}>0.05)$. The stroke volume (SV) increased significantly in CTG at rest and after workload $(\mathrm{P} \leq 0.05)$. The cardiac output (CO) did not change in both groups $(\mathrm{P}>0.05)$. The $\mathrm{VO}_{2 \max }$ absolute and relative increased significantly in $\mathrm{CTG}(\mathrm{P} \leq 0.05)$.

Significant difference observed between groups in SBP, SV, SVR and $\mathrm{VO}_{2 \max }$ absolute and relative $(\mathrm{P} \leq 0.05)$. 
Table 1. General characteristics of the subjects

\begin{tabular}{lll}
\hline Variables & Training group & Control group \\
\hline Age (year) & $18.4 \pm 0.7$ & $18.9 \pm 0.6$ \\
Height $(\mathrm{cm})$ & $175.7 \pm 5.4$ & $173.2 \pm 5.3$ \\
Weight $(\mathrm{kg})$ & $71.3 \pm 5.1$ & $72.6 \pm 4.5$ \\
\hline
\end{tabular}

Table 2. Values of central hemodynamic variables in the training and control groups

\begin{tabular}{|c|c|c|c|c|c|}
\hline \multirow{2}{*}{ Variables } & \multirow{2}{*}{$\begin{array}{l}\text { Groups } \\
\text { Status }\end{array}$} & \multicolumn{2}{|c|}{ Continuous training } & \multicolumn{2}{|l|}{ Control } \\
\hline & & Pre (0 wks.) & Post (8 wks.) & Pre (0 wks.) & Post (8 wks.) \\
\hline SBP, & Rest & $125.0 \pm 8.7$ & $115.7 \pm 4,1^{*, * *}$ & $121.6 \pm 2.8$ & $120.0 \pm 5.7$ \\
\hline $\mathrm{mmHg}$ & Step-test & $143.6 \pm 5.9$ & $135.0 \pm 8.4^{*}$ & $145.0 \pm 9.8$ & $142.0 \pm 10.3$ \\
\hline DBP, & Rest & $83.7 \pm 10.0$ & $77.8 \pm 5.6$ & $80.5 \pm 8.5$ & $77.3 \pm 4.8$ \\
\hline $\mathrm{mmHg}$ & Step-test & $79.3 \pm 11.8$ & $76.5 \pm 6.2$ & $82.6 \pm 2.9$ & $75.1 \pm 7.5$ \\
\hline$H R$, & Rest & $73.2 \pm 6.0$ & $65.0 \pm 5.3^{*}$ & $71.3 \pm 7.5$ & $68.3 \pm 5.4$ \\
\hline beats. $\min ^{-1}$ & Step-test & $127.0 \pm 10.5$ & $120.9 \pm 7.1$ & $124.2 \pm 20.7$ & $125.0 \pm 24.2$ \\
\hline SV, & Rest & $85.5 \pm 7.5$ & $102.5 \pm 10.1^{*}$ & $93.5 \pm 10.9$ & $96.3 \pm 14.2$ \\
\hline $\mathrm{ml}$ & Step-test & $83.5 \pm 17.3$ & $101.5 \pm 6.1^{*}$ & $92.9 \pm 14.6$ & $91.8 \pm 24.1$ \\
\hline $\mathrm{CO}$ & Rest & $6.2 \pm 1.8$ & $7.6 \pm 2.2$ & $6.6 \pm 1.4$ & $6.5 \pm 0.9$ \\
\hline I. $\min ^{-1}$ & Step-test & $10.6 \pm 2.9$ & $12.2 \pm 1.7$ & $11.5 \pm 1.9$ & $11.4 \pm 1.6$ \\
\hline SVR, & Rest & $961.3 \pm 143.0$ & $863.1 \pm 107.8^{* *}$ & $1072.2 \pm 145.3$ & $1056.7 \pm 128.2$ \\
\hline dynes $\cdot \mathrm{sec} \cdot \mathrm{cm}^{5}$ & Step-test & $925.3 \pm 135.0$ & $850.7 \pm 112.0^{* *}$ & $1026.9 \pm 126.3$ & $1032.5 \pm 127.8$ \\
\hline $\begin{array}{l}\text { VO }{ }_{2 \max } \text { absolute, } \\
\text { I.min } \text { min }^{-1}\end{array}$ & Step-test & $4.1 \pm 0.6$ & $4.7 \pm 0.5^{* * * *}$ & $3.6 \pm 1.1$ & $3.7 \pm 0.7$ \\
\hline 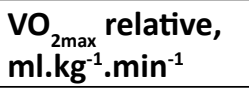 & Step-test & $52.6 \pm 8.8$ & $62.9 \pm 6.3^{*, * *}$ & $48.1 \pm 10.9$ & $51.4 \pm 11.5$ \\
\hline
\end{tabular}

Note: Significantly different from beginning at statistical level: * in groups, ${ }^{* *}$ between groups $-\mathrm{P} \leq 0.05$

\section{Discussion}

Hypertension is the most important risk factor for cardiovascular morbidity and mortality [29] and it is also known that increased resting heart rate is an independent risk factor associated with cardiovascular fatality [30]. In addition, increased heart rate may also increase atherosclerosis, cardiac ischemia, cardiac hypertrophy and heart failure $[31,32]$. Studies showed that the patients with high-normal blood pressure (systolic blood pressure 130-139 mmHg, diastolic blood pressure 85-89 mmHg, or both) were twice as likely to have a cardiovascular disease risk compared to those at low levels $[33,34,35]$. Liu S et al. [36] reported significantly decrease in SBP and DBP after acute and chronic exercise. In our study SBP decreased from $125.0 \pm 8.7$ to $115.7 \pm 4.1 \mathrm{mmHg}$ at rest and decreased from $143.6 \pm 5.9$ to $135.0 \pm 8.4$ at workload (step-test) in training group significantly, along with decrease in DBP, but there was no significant mode. It was also observed that systolic and diastolic blood pressures of CTG were closed to cardiovascular disease risk before training, but at the end of the study there was a positive improvement indicating that subjects in exercise group were away from the risk of cardiovascular disease. It can be argued that the regular exercise of aerobic with moderate intensity causes positive developments in systolic and diastolic blood pressures [37, 38]. Jennings et al. [39] and Whelton et al. [40] reported that higher exercise more than five times per week and $>60$ min did not produce a greater reduction in BP in hypertensive patients compared with three to four times per week and 30-60 min. The relation of long term training intensity to BP reductions is unclear, with some authors observing more change with an intensity $>70 \%$ $\mathrm{VO}_{2 \max }$ [41], whereas another sees no intensity effect [11]. Nevertheless, the time course of the resting BP change allowed us to verify that the greatest BP reduction was achieved at the end of the 8 weeks of training [36].

Duncker and Bache, [42] reported that during physical activity increase in HR is highest of myocardial oxygen consumption is responsible. In the present study, HR decreased significantly at rest. It is consonant with research of Rodrigues et al. [43] and Chaudhary et al. [44]. SV increased at rest and workload. Trilk et al. [45] demonstrated that interval training improved cardiac function by reducing $\mathrm{HR}$ and increasing SV. After 8 weeks continuous training the $\mathrm{CO}$ showed no significantly increase. In result of endurance training is eccentric reformation change on heart. It is highlight with increase the internal dimension and a reason of the large left ventricular volume, and high SV [46, 47]. In addition, in the CTG was shown an increase in SV with a decrease 
in heart rate. This mechanism was shown as the result that might maintain a stable resting $\mathrm{CO}$. It can be said, increasing $\mathrm{SV}$ is maintained with decreasing heart rate, and conversely. Also, regular exercise makes the flow of the venous blood, thus increasing the amount of blood returning to the heart, which increases $\mathrm{CO}$ [48].

Mean arterial blood pressure increases in result of dynamic exercise. Increase in mean arterial pressure results from an increase in $\mathrm{CO}$ and decrease in total peripheral resistance $[49,50]$. The long term exerciseassociated BP reduction is mainly due to decreased total peripheral resistant that is not met by an increase in $\mathrm{CO}$ [8]. The mechanism in which exercises have effect on blood pressure is different depending on intensity, time, and training types, but it is known that decreasing blood pressure happens due to decreasing activity of sympathetic nervous system and decreasing the peripheral resistance [51]. That confirmed with decrease in SVP at rest and after step-test. After 8-weeks the SVP in CGT was significantly less than control group.

$\mathrm{VO}_{2 \max }$ is accepted as a demonstration of cardiovascular health and cardiopulmonary fitness [52]. One of the aims of our study was to increase $\mathrm{VO}_{2 \max }$ by applying moderateintensity continuous programs at $65-70 \%$ in addition, improving left ventricular cardiac parameters (CO \& SV) [54]. At the end of the study, there was a positive increase in $\mathrm{VO}_{2 \max }$ (absolute and relative) in CTG (at rest and after workload) and resulting in positive improvements in SV. For this reason, we can say that regular exercises on young male in training group benefit cardiorespiratory fitness and primary and another protection of cardiovascular diseases [54]. Mazurek K et al. [55] reported significantly increase in $\mathrm{VO}_{2 \max }$ absolute and $\mathrm{VO}_{2 \max }$ related in college females after interval and continuous aerobic training. Tjonna et al. [56] showed the intensive endurance training significantly improves $\mathrm{VO}_{2 \max }$ after 10 -week of training in healthy men. After 8-weeks $\mathrm{VO}_{2 \max }$ in CGT was significantly higher than $\mathrm{CG}$.

In response to aerobic training, the body reacts by increased oxygen uptake, $\mathrm{HR}, \mathrm{CO}$, initial peak and then plateau in SV. Peripheral vascular resistance is reduced and SBP progressively increases along with a decreased DBP [57]. It is consistent with the result of our study in terms of step-test.

\section{Conclusion}

The result of this study demonstrated that a positive effect through moderate-intensity continuous countryside jogging on $\mathrm{VO}_{2 \max }$ and cardiac function. Also, the exercise duration (45 min) and intensity $\left(65-70 \% \mathrm{VO}_{2 \max }\right)$ prescribed in this study were expected to yield the optimal $\mathrm{BP}$ reduction as well as improvement in aerobic power especially for sedentary people.

\section{Conflicts of Interest}

The author declare that they have no conflict of interest.

\section{References}

1. Li J, Siegrist J. Physical activity and risk of cardiovascular disease: a meta-analysis of prospective cohort studies. Int J Environ Res Public Health, 2012; 9: 391-407. https://doi.org/10.3390/ijerph9020391

2. Otsuki T, Maeda S, Iemitsu M, Saito Y, Tanimura Y, Ajisaka R, et al. Systemic arterial compliance, systemic vascular resistance, and effective arterial elastance during exercise in endurance-trained men. Am J Physiol Regul Integr Comp Physiol, 2008; 295: R228-R235. https://doi.org/10.1152/ajpregu.00009.2008

3. Hottenrott K, Ludyga S, Schulze S. Effects of High Intensity Training and Continuous Endurance Training on Aerobic Capacity and Body Composition in Recreationally Active Runners. J Sports Sci Med, 2012; 11(3): 483-488.

4. Reimers CD, Knapp G, Reimers AK. Does Physical Activity Increase Life Expectancy? A Review of the Literature. Journal of Aging Research, 2012;2012:1-9. https://doi.org/10.1155/2012/243958

5. ChobanianAV,Bakris GL, BlackHR, Cushman WC, GreenLA, Izzo JL, et al. Seventh Report of the Joint National Committee on Prevention, Detection, Evaluation, and Treatment of High Blood Pressure. Hypertension, 2003;42:1206-52. https://doi.org/10.1161/01.HYP.0000107251.49515.c2

6. Cornelissen VA, Fagard RH. Effects of endurance training on blood pressure, blood pressureregulating mechanisms, and cardiovascular risk factors. Hypertension, 2005; 46(4): 667-675. https://doi.org/10.1161/01.HYP.0000184225.05629.51

7. Punia S, Kulandaivelan S, Singh V, Punia V. Effect of Aerobic Exercise Training on Blood Pressure in Indians:
Systematic Review. Int $J$ Chronic Dis, 2016; (2):1-8. https://doi.org/10.1155/2016/1370148

8. Cornelissen VA, Smart NA. Exercise training for blood pressure: a systematic review and meta-analysis. Journal of the American Heart Association, 2013; 2(1): e004473. https://doi.org/10.1161/JAHA.112.004473

9. Sagelv EH, Hammer T, Hamsund T, Rognmo $K$, Pettersen SA, Pedersen S. High Intensity Long Interval Sets Provides Similar Enjoyment as Continuous Moderate Intensity Exercise. The Tromsø Exercise Enjoyment Study. Front Psychol, 2019; 10:1788. https://doi.org/10.3389/fpsyg.2019.01788

10.Halliwill JR. Mechanisms and clinical implications of postexercise hypotension in humans. Exerc Sport Sci Rev, 2001; 29(2): 65-70.

11.MacDonald JR. Potential causes, mechanisms, and implications of post exercise hypotension. $J$ Hum Hypertens, 2002; 16(4): 225-236. https://doi.org/10.1038/sj.jhh.1001377

12.Horn P, Ostadal P, Ostadal B. Rowing Increases Stroke Volume and Cardiac Output to a Greater Extent Than Cycling. Physiol Res, 2015; 64: 203-207. https://doi.org/10.33549/physiolres.932853

13.Lakin R, Notarius C, Thomas S, Goodman J. Effects of moderate-intensity aerobic cycling and swim exercise on post-exertional blood pressure in healthy young untrained and triathlon-trained men and women. Clinical Science, 2013; 125(12): 543-553. https://doi.org/10.1042/CS20120508

14.Kobe J, Mishra N, Arya VK, Al-Moustadi W, Nates W, Kumar B. Cardiac output monitoring: Technology 
and choice. Ann Card Anaesth, 2019; 22(1): 6-17. https://doi.org/10.4103/aca.ACA_41_18

15.Cramer H, Lauche R, Haller H, Steckhan N, Michalsen A, Dobos G. Effects of yoga on cardiovascular disease risk factors: A systematic review and meta-analysis. Int J Cardiol, 2014; 173: 170-183.

16.Hartaigh BO, Gill TM, Shah I, Hughes AD, Deanfield JE, $\mathrm{Kuh} \mathrm{D}$, et al. Association between resting heart rate across the life course and all-cause mortality: Longitudinal findings from the Medical Research Council (MRC) National Survey of Health and Development (NSHD). J Epidemiol Community Health, 2014; 68: 883-889.

17.Huang G, Shi X, Davis-Brezette JA, Osness WH. Resting heart rate changes after endurance training in older adults: A meta-analysis. Med Sci Sports Exerc, 2005; 37: 1381-1386.

18.Zheng G, Li S, Huang M, Liu F, Tao J, Chen L. The effect of Tai Chi training on cardiorespiratory fitness in healthy adults: A systematic review and meta-analysis. PLoS ONE, 2015; 10: e0117360. https://doi.org/10.1371/journal.pone.0117360

19. Baggish AL. The athlete's heart. In: Ostadal B, and Dhalla NS, editors. Cardiac adaptation. Advances in Biochemistry in Health and Disease. New York: Springer Science and Business Media; 2013.

20.Slørdahl SA, Madslien, VO, Støylen A, Kjos A, Helgerud J, Wisløff U. Atrioventricular plane displacement in untrained and trained females. Medicine and Science in Sports and Exercise, 2004; 36(11): 1871-1875. https://doi.org/10.1249/01.MSS.0000145444.01292.3D

21.Ochsner G, Wilhelm MJ, Amacher R, Petrou A, Cesarovic N, Staufert S, et al. In Vivo Evaluation of Physiologic Control Algorithms for Left Ventricular Assist Devices Based on Left VentricularVolumeorPressure.ASAIOJ,2017;63(5):568-577. https://doi.org/10.1097/MAT.0000000000000533

22.WarburtonDE, GledhillN, JamnikVK, KripB, CardN. Induced hypervolemia, cardiac function, $\mathrm{VO} 2 \mathrm{max}$, and performance of elite cyclists. Med Sci Sports Exerc, 1999; 31: 800-808. https://doi.org/10.1097/00005768-199906000-00007

23.Daussin FN, Zoll J, Dufour SP, Ponsot E, Lonsdorfer-Wolf E, Doutreleau S, et al. Effect of interval versus continuous training on cardiorespiratory and mitochondrial functions: relationship toaerobic performanceimprovementsinsedentary subjects. American Journal of Physiology-Regulatory, Integrative and Comparative Physiology 2008;295:R264-72. https://doi.org/10.1152/ajpregu.00875.2007

24.Helgerud J, Høydal K, Wang E, Karlsen T, Berg P, Bjerkaas $M$, et al. Aerobic high-intensity intervals improve VO2max more than moderate training. Med Sci Sports Exerc, 2007; 39(4): 665-671. https://doi.org/10.1249/mss.0b013e3180304570

25.Rognmo Ø, Hetland E, Helgerud J, Hoff J, Slørdahl SA. High intensity aerobic interval exercise is superior to moderate intensity exercise for increasing aerobic capacity in patients with coronary artery disease. Eur $J$ Cardiovasc Prev Rehabil, 2004; 11(3): 216-22. https://doi.org/10.1097/01.hjr.0000131677.96762.0c

26. Wisløff U, Støylen A, Loennechen JP, Bruvold M, Rognmo O, Haram PM, et al. Superior cardiovascular effect of aerobic interval training versus moderate continuous training in heart failure patients: a randomized study. Circulation, 2007; 115(24): 3086-3094. https://doi.org/10.1161/CIRCULATIONAHA.106.675041

27.Bartels MN, Bourne GW, Dwyer JH. High-intensity exercise for patients in cardiac rehabilitation after myocardial infarction. Physical Medicine and Rehabilitation, 2010; 2(2):
151-155.

28. Vilarinho R, Caneiras C, Mesquita Montes A. Measurement properties of step tests for exercise capacity in COPD: A systematic review. Clin Rehabil, 2020;35:578-588. https://doi.org/10.1177/0269215520968054

29.Kearney PM, Whelton M, Reynolds K, Muntner P, Whelton PK, He J. Global burden of hypertension: analysis of worldwide data Lancet, 2005; 365(9455): 217-223. https://doi.org/10.1016/S0140-6736(05)17741-1

30.Brito Díaz B, Alemán Sánchez JJ, Cabrera de León A. Frecuencia cardiaca en reposo y enfermedad cardiovascular [Resting heart rate and cardiovascular disease]. Med Clin (Barc), 2014; 143(1): 34-8. (In Spanish). https://doi.org/10.1016/j.medcli.2013.05.034

31.Palatini P. Heart rate as an independent risk factor for cardiovascular disease: current evidence and basic mechanisms. Drugs, 2007; 67(2):3-13. https://doi.org/10.2165/00003495-200767002-00002

32. Zhang GQ, Zhan W. Heart rate, lifespan, and mortality risk Ageing. Res Rev, 2009; 8(1): 52-60. https://doi.org/10.1016/j.arr.2008.10.001

33.VasanRS,LarsonMG,LeipEP,EvansJC,O'DonnellCJ,Kannel $\mathrm{WB}$, et al. Impact of high-normal blood pressure on the risk of cardiovascular disease. NEngl JMed, 2001;345(18): 1291-7. https://doi.org/10.1056/NEJMoa003417

34.Ridker PM, Pradhan A, MacFadyen JG, Libby P, Glynn RJ. Cardiovascular benefits and diabetes risks of statin therapy in primary prevention: an analysis from the JUPITER trial. Lancet, 2012; 380(9841): 565-571. https://doi.org/10.1016/S0140-6736(12)61190-8

35. Rossow L, Yan H, Fahs CA, Ranadive SM, Agiovlasitis $\mathrm{S}$, Wilund $\mathrm{KR}$, et al. Postexercise Hypotension in an Endurance-Trained Population of Men and Women Following High-Intensity Interval and Steady-State Cycling. American Journal of Hypertension, 2010; 23(4): 358-367. https://doi.org/10.1038/ajh.2009.269

36.Liu S, Goodman J, Nolan R, Lacombe S, Thomas SG. Blood Pressure Responses to Acute and Chronic Exercise Are Related in Prehypertension. Med Sci Sports Exerc, 2012; 44(9): 1644-1652. https://doi.org/10.1249/MSS.0b013e31825408fb

37.Sillanpää E, Häkkinen A, Punnonen K, Häkkinen K, Laaksonen DE. Effects of strength and endurance training on metabolic risk factors in healthy 40-65-yearold men. Scand J Med Sci Sports, 2009; 19(6): 885-895. https://doi.org/10.1111/j.1600-0838.2008.00849.x

38.Fagard RH. Exercise characteristics and the blood pressure response to dynamic physical training. Med Sci Sports Exerc, 2001; 33(6): 484-92. https://doi.org/10.1097/00005768-200106001-00018

39.JenningsGL,DeakinG,KornerP,MeredithI,KingwellB,Nelson $\mathrm{L}$. What is the dose-response relationship between exercise training and blood pressure? Ann Med, 2009; 23(3): 313-318. https://doi.org/10.3109/07853899109148066

40. Whelton SP, Chin A, Xin X, He J. Effect of aerobic exercise on blood pressure: a meta-analysis of randomized, controlled trials. Ann Intern Med, 2002; 136: 493-503. https://doi.org/1 0.7326/0003-4819-136-7-20020402000006

41.Hagberg JM, Park JJ, Brown MD. The role of exercise training in the treatment of hypertension: an update. Sports Med, 2000; 30(3): 193-206. https://doi.org/10.2165/00007256-200030030-00004

42.DunckerDJ,BacheRJ.RegulationofCoronaryBloodFlowDuring Exercise. Physiological Reviews, 2008; 88(3): 1009-1086. 
https://doi.org/10.1152/physrev.00045.2006

43. Rodrigues AC, de Melo Costa J, Alves GB, Ferreira da Silva D, Picard MH, Andrade JL, et al. (2006). Left ventricular function after exercise training in young men. Am J Cardiol, 2006; 97(7): 1089-92. https://doi.org/10.1016/j.amjcard.2005.10.055

44.Chaudhary S, Kang MK, Sandhu JS. The effects of aerobic versus resistance training on cardiovascular fitness in obese sedentary females. Asian J Sports Med, 2010; 1(4): 177-184. https://doi.org /10.5812/asjsm.34835

45.Trilk JL, Singhal A, Bigelman KA, Cureton KJ. Effect of sprint interval training on circulatory function during exercise in sedentary, overweight/obese women. European journal of applied physiology, 2011; 111: 1591-7. https://doi.org/10.1007/s00421-010-1777-z

46.Maron BJ, Pelliccia A. The heart of trained athletes: cardiac remodeling and the risks of sports, including sudden death. Circulation, 2006; 114: 1633-1644. https://doi.org/10.1161/CIRCULATIONAHA.106.613562

47.Paterick TE, Gordon T,Spiegel D. Echocardiography: profiling of theathlete'sheart.JAmSocEchocardiogr,2014;27:940-948. https://doi.org/10.1016/j.echo.2014.06.008

48.Hoogsteen J, Hoogeveen A, Schaffers H, Wijn PF, van Hemel NM, van der Wall EE. Myocardial adaptation in different endurance sports: an echocardiographic study. Int $J$ Cardiovasc Imaging, 2004; 20: 19-26. https://doi.org/10.1023/B:CAIM.0000013160.79903.19

49.da Nobrega AC. The subacute effects of exercise: concept, characteristics, and clinical implications. Exerc Sport Sci Rev, 2005; 33: 84-87. https://doi.org/10.1097/00003677-200504000-00005

50.Ridker PM. On evolutionary biology, inflammation, infection, and the causes of atherosclerosis. Circulation, 2002; 105: 2-4. https://doi.org/10.1161/circ.105.1.2
51.CavalcanteMA,BombigMT,LunaFilhoB, CarvalhoAC, Paola AA, Póvoa R. Quality of life of hypertensive patients treated at an outpatient clinic. Arq Bras Cardiol, 2007; 89: 245-250. https://doi.org/10.1590/s0066-782x2007001600006

52.Doijad VP, Kample P, Surdi AD. Effect of Yogic exercises on aerobic capacity (VO2 max). Int $J$ Recent Trends Sci Technol, 2013; 6(3): 119-121. https://doi.org/10.5958/j.2320-608X.1.2.010

53.Karavirta L, Häkkinen K, Kauhanen A, Arija-Blázquez A, Sillanpää E, Rinkinen N, et al. Individual responses to combined endurance and strength training in older adults. Med Sci Sports Exercises, 2011; 43(3): 484-490. https://doi.org/10.1249/mss.0b013e3181f1bf0d

54.Lavie CJ, Church TS, Milani RV, Earnest CP, et al. Impact of physical activity, cardiorespiratory fitness, and exercise training on markers of inflammation. J Cardiopulm Rehabil Prev, 2011; 31(3): 137-145. https://doi.org/10.1097/HCR.0b013e3182122827

55.Mazurek K, Krawczyk K, Zmijewski P, Norkowski H, Czajkowska A. Effects of aerobic interval training versus continuous moderate exercise programme on aerobic and anaerobic capacity, somatic features and blood lipid profile in collegate females. Annals of Agricultural and Environmental Medicine, 2014; 21: 844-849. https://doi.org/10.5604/12321966.1129949

56.Tjonna AE, Leinan IM, Bartnes AT, Jenssen BM, Gibala MJ, et al. Low- and High-Volume of Intensive Endurance Training Significantly Improves Maximal Oxygen Uptake after 10-Weeks of Training in Healthy Men. PLoS ONE, 2013; 8(5): e65382. https://doi.org/10.1371/journal.pone.0065382

57.MekaN,KatragaddaS,CherianB,AroraRR.Enduranceexercise and resistance training in cardiovascular disease. Therapeutic Advances in Cardiovascular Disease, 2008; 2(2): 115-121. https://doi.org/10.1177/1753944708089701

\section{Information about the author:}

Javad Mahdiabadi; Assistant Professor in Exercise Physiology; https://orcid.org/0000-0002-2442-3206; j_mahdiabadi@yahoo. com; Toos Institute of Higher Education, Mashhad, Iran.

Cite this article as:

Mahdiabadi J. The effect of 8 weeks moderate-intensity continuous training on central hemodynamics and $\mathrm{VO}_{2 \max }$ in nonathlete male. Physical Education of Students, 2021;25(3):172-177. https://doi.org/10.15561/20755279.2021.0305

This is an Open Access article distributed under the terms of the Creative Commons Attribution License, which permits unrestricted use, distribution, and reproduction in any medium, provided the original work is properly cited http://creativecommons.org/licenses/by/4.0/deed.en

Received: 12.05 .2021

Accepted: 18.06.2021; Published: 30.06.2021 